Research Article

\title{
Freezing-Thawing Damage Mechanism of Coal Gangue Concrete Based on Low-Field Nuclear Magnetic Resonance, Scanning Electron Microscopy, and $\mathbf{N}_{2}$ Adsorption
}

\author{
Bowen Hou, ${ }^{1}$ Jisheng Qiu ${ }^{D},{ }^{1}$ Peng Guo, ${ }^{2}$ Xujun Gao, ${ }^{2}$ and Ruyi Zhang ${ }^{1}$ \\ ${ }^{1}$ School of Architecture and Civil Engineering, Xi'an University of Science and Technology, 710000 Xi'an, China \\ ${ }^{2}$ Powerchina Northwest Engineering Corporation Limited, 710065 Xi'an, China \\ Correspondence should be addressed to Jisheng Qiu; qiujisheng@xust.edu.cn
}

Received 26 September 2020; Revised 12 December 2020; Accepted 2 January 2021; Published 4 February 2021

Academic Editor: José Aguiar

Copyright (c) 2021 Bowen Hou et al. This is an open access article distributed under the Creative Commons Attribution License, which permits unrestricted use, distribution, and reproduction in any medium, provided the original work is properly cited.

To study waterborne frost heaving failure mechanism of coal gangue ceramsite concrete (CGCC) under freeze-thaw cycles, capillary water absorption test, nonmetallic ultrasonic testing test, low-field nuclear magnetic resonance (LNMR) test, $\mathrm{N}_{2}$ adsorption test, and other tests were used to determine the effect of freeze-thaw cycles on the porosity, relative dynamic elastic modulus (RDM), and capillary adsorption rate of different coal gangue ceramsite (MT) replacement rates $(0,20 \%, 40 \%$, and $60 \%)$. Combining the changes of performance indexes and the changes of micropore structure under freeze-thaw cycles, the freeze-thaw failure mechanism of normal concrete (OC) and CGCC was analyzed. In view of the particularity of MT material, the method based on pore size is put forward to distinguish $\mathrm{M}$ pores from T pores, and the reasons for different properties are analyzed from the microperspective. The results show that the freeze-thaw cycle changes the microstructure of coal gangue concrete and has an obvious influence on its properties. And when the replacement rate is $40 \%$, degradation mitigation performance is optimal. Due to the particularity of MT shape, T pores are dominant in coal gangue concrete matrix, which is different from the microstructure of ordinary concrete and can reduce the structural deterioration caused by freeze-thaw. The research results of this paper can provide a reference for the research and application of CGCC in freeze-thaw environment.

\section{Introduction}

Coal gangue is a kind of solid waste which is associated with coal in the coal formation process. It is also a kind of black gray rock with low carbon content and harder than coal. Coal gangue is the industrial solid waste with the largest discharge volume, resulting in such problems as land occupation, environmental pollution, ecological destruction, and high treatment costs [1-4]. Therefore, it is of great economic, social, and environmental significance to make use of the waste coal gangue to produce concrete. Coal gangue mainly comes from the "three northern regions," namely, north China, northeast China, and northwest China [5], which are located in the severe cold area. In order to make effective use of local material of gangue, the application area of gangue concrete is also concentrated in the "three north regions" area. Therefore, the research focuses on the frost resistance and frost heaving failure mechanism of coal gangue concrete under freeze-thaw cycles.

Many scholars have conducted a large number of studies on saturated concrete. Bao et al. [6] studied the influence of several factors including the quality and dosages of recycled coarse aggregates, water saturation degree, pore structure, and the mineral admixtures on the frost resistance property of RAC and analyzed the frost resistance of recycled aggregate concrete members. Bai et al. [7] discussed the influence mechanism of pore water pressure on compressive strength of concrete under complicated stress conditions. Based on the equation of effective stress of Terzaghi, the effective stress principle expression in accordance with characteristics of concrete microstructure was established. The results show that the pore water pressure changes the 
loading process of the real stress of the concrete matrix in the stress space so that it changes the compressive strength corresponding to the peak stress of concrete material. Du and Liu [8] studied the effect of pore water on the effective elastic modulus, strength, and other mechanical properties of concrete and obtained the quantitative relationship between effective bulk modulus and porosity of saturated concrete based on the theory of the three-phase sphere model. The results showed that the pore structure of saturated concrete changes obviously under freeze-thaw, in which the total porosity increases, the number of large pores increases, and the number of small holes decreases. And the greater the degree of saturation, the more obvious this destructive effect. While coal gangue ceramsite has the advantages of low density, light weight, and high strength [9], it is considered to make coal gangue into ceramsite to replace the coarse aggregate in ordinary concrete, in order to slow down the change of pore structure of coal gangue concrete in the freeze-thaw cycle environment.

In the previous research, this research group also carried out an experiment on the frost resistance durability of coal gangue concrete. The experimental results showed that the frost resistance of coal gangue concrete gradually deteriorates with the increase of the coal gangue replacement ratio, which is not suitable for cold and humid areas. In order to improve this problem, this paper used coal gangue ceramsite to replace parts of coarse aggregate and explored the durability and frost heaving failure mechanism of CGCC through capillary water absorption performance, durability index, and microscopic pore structure change under saturated freeze-thaw cycle action. This paper aims at providing a reference and basis for the application of coal gangue and improving the frost resistance of coal gangue concrete.

\section{Materials and Methods}

2.1. Test Materials. The following materials were used: Cement: P.O42.5 R ordinary Portland cement of Shaanxi Qinling Cement Co. Ltd. The detailed basic properties are shown in Table 1. Coal gangue ceramsite, made of coal gangue produced in a coal mine in Shenmu City, Shaanxi Province, China, with a particle size of $4 \sim 6 \mathrm{~mm}$, an apparent density of $1923 \mathrm{~kg} / \mathrm{m}^{3}$, a water absorption rate of $6.68 \%$, and a crushing index of $20.8 \%$. As to coal gangue, the detailed relative contents of chemical constituents are shown in Table 2, and the XRD pattern is shown in Figure 1. Gravel included ordinary crushed stone from Xi'an city nearby, with particle gradation ranging from $5 \mathrm{~mm}$ to $16 \mathrm{~mm}$, the apparent density of $2870 \mathrm{~kg} / \mathrm{m}^{3}$, the water absorption rate of $0.6 \%$, the mud content of $0.2 \%$, and the crushing index of $8 \%$. Sand used was ordinary river sand, with the fineness modulus of 2.7 , the apparent density of $2610 \mathrm{~kg} / \mathrm{m}^{3}$, the packing density of $1460 \mathrm{~kg} / \mathrm{m}^{3}$, and the mud content of $1 \%$. Water used was ordinary tap water.

2.2. Mixture Ratio of Specimens. Concrete specimens are with a water-cement ratio of 0.45 and a sand ratio of 0.35 . And MT replacement ratios are $0 \%, 20 \%, 40 \%$, and $60 \%$, respectively. The mixture ratio of tests in the laboratory is shown in Table 3. C0, C0M2, C0M4, and C0M6 in the table, respectively, indicate CGCC with $\mathrm{MT}$ replacement ratios of $0,20 \%, 40 \%$, and $60 \%$.

\subsection{Test Method}

2.3.1. Mechanical Strength Test. Test specimens were made according to the design mixture ratio in Table 3 and the Chinese National Standard, "standard for test method of mechanical properties on ordinary concrete" (GB/T500812016). Mechanical strength test of coal gangue concrete adopted cubic specimens of $100 \mathrm{~mm} \times 100 \mathrm{~mm} \times 100 \mathrm{~mm}$. After demolding, the specimens were put into a standard maintenance room for 28 days.

2.3.2. Freeze-Thaw Test. The specimens were tested by the "Rapid Freezing Method (RFG)," which is derived from "standard for test methods of long-term performance and durability of ordinary concrete" (GB/T50082-2009, Chinese National Standard). Before the test, the specimens which have finished the maintenance period (28 days) are immersed in water and are placed in the freeze-thaw tank when specimens are saturated (4 days). Tests of mass loss and relative dynamic elastic modulus (RDM) were tested with cube specimens with dimensions of $100 \mathrm{~mm} \times 100 \mathrm{~mm}$ $\times 400 \mathrm{~mm}$. Every 10 freeze-thaw cycles, $100 \mathrm{~mm} \times 100 \mathrm{~mm}$ $\times 100 \mathrm{~mm}$ part of specimens is taken out and dried, and then the capillary water absorption test is carried out.

2.3.3. Capillary Water Absorption Test. The test was performed according to ASTM C1585 [10]. Before the test, $100 \mathrm{~mm} \times 100 \mathrm{~mm} \times 100 \mathrm{~mm} \times 100 \mathrm{~mm}$ concrete specimens were evenly coated with epoxy resin all around and maintained for 28 days. After the epoxy resin was dried, the specimens were put in the drying oven with a temperature of $105^{\circ} \mathrm{C}$ and dried to constant weight $(48 \mathrm{~h})$ before being taken out. When the temperature of the specimen dropped to room temperature, the pouring surface was sealed with plastic film, and the specimen was placed on the support of the container. The untreated surface of specimens is made to be in contact with water and liquid level is $1-3 \mathrm{~mm}$ higher than the bottom of specimens, which ensures that the water absorption process is one-dimensional water absorption.

\subsubsection{Nuclear Magnetic Resonance (NMR) Tests. NMR tests} were tested with cylinder specimens.

2.4. Test Equipment. Pore structure test was tested with MacroMR12-150H-I NMR instrument (diameter of probe coil of $150 \mathrm{~mm}$, magnet temperature of $30^{\circ} \mathrm{C}$, and sampling rate of $50 \mathrm{MHz}$ ) and Accelerated Surface Area and Porosimetry System instrument (ASAP 2020) (pore size of nitrogen adsorption ranging from $1.7 \mathrm{~mm}$ to $300 \mathrm{~nm}$ ). Microscopical observations were carried out with JSM6460LV scanning electron microscope (magnification: 5 300000). Freeze-thaw cycle tests were tested with KDR-V9 
TABLe 1: Basic properties of $\mathrm{P} \bullet \mathrm{O} 42.5 \mathrm{R}$ ordinary Portland cement.

\begin{tabular}{|c|c|c|c|c|c|c|c|c|}
\hline \multirow[t]{2}{*}{ Setting time } & \multicolumn{2}{|c|}{$\begin{array}{c}\text { Flexural } \\
\text { strength }(\mathrm{MPa})\end{array}$} & \multicolumn{2}{|c|}{$\begin{array}{c}\text { Compressive } \\
\text { strength }(\mathrm{MPa})\end{array}$} & \multirow[t]{2}{*}{ Fine-grain (\%) } & \multirow{2}{*}{$\begin{array}{c}\text { Loss on } \\
\text { ignition (LOI) }(\%)\end{array}$} & \multirow[t]{2}{*}{$\mathrm{MgO}$ content (\%) } & \multirow{2}{*}{$\mathrm{SO}_{3}$ content (\%) } \\
\hline & 3 days & 28 days & 3 days & 28 days & & & & \\
\hline $\begin{array}{l}\text { Initial setting time: } 65 \mathrm{~min} \\
\text { Final setting time: } 5 \mathrm{~h}\end{array}$ & 4.3 & 7.9 & 24.0 & 43.5 & 3.4 & 2.7 & 2.2 & 2.4 \\
\hline
\end{tabular}

TABLE 2: Relative contents of chemical constituents of coal gangue.

\begin{tabular}{lcccccc}
\hline Components & $\mathrm{SiO}_{2}$ & $\mathrm{Fe}_{2} \mathrm{O}_{3}$ & $\mathrm{AL}_{2} \mathrm{O}_{3}$ & $\mathrm{CaO}$ & $\mathrm{MgO}$ & $\mathrm{C}, \mathrm{Na}, \mathrm{K}$, and other oxides \\
\hline $\begin{array}{l}\text { Relative } \\
\text { content (\%) }\end{array}$ & 48.12 & 6.26 & 36.34 & 6.16 & 0.95 & 2.17 \\
\hline
\end{tabular}

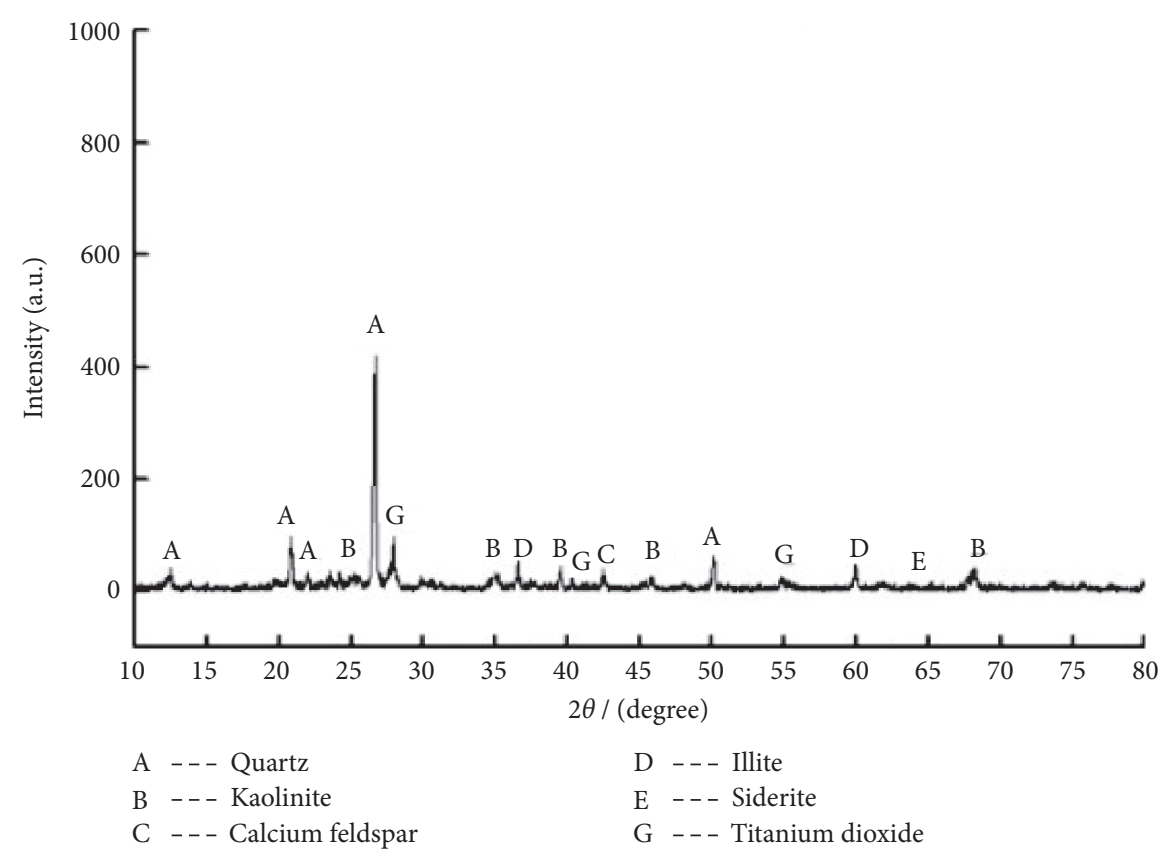

FIgURE 1: XRD diffraction pattern of coal gangue.

TABLE 3: Mixture ratio of coal gangue ceramsite concrete.

\begin{tabular}{lcccccc}
\hline Specimen type & Cement $\left(\mathrm{kg} \cdot \mathrm{m}^{-3}\right)$ & Water $\left(\mathrm{kg} \cdot \mathrm{m}^{-3}\right)$ & Water-cement ratio & Gravel $\left(\mathrm{kg} \cdot \mathrm{m}^{-3}\right)$ & Coal gangue $_{\left(\mathrm{kg} \cdot \mathrm{m}^{-3}\right)}$ & Sand $\left(\mathrm{kg} \cdot \mathrm{m}^{-3}\right)$ \\
\hline C0 & 355 & 160 & 0.45 & 1225 & 0 & 660 \\
C0M2 & 355 & 160 & 0.45 & 980 & 768 & 660 \\
C0M4 & 355 & 160 & 0.45 & 735 & 337 & 660 \\
C0M6 & 355 & 160 & 0.45 & 490 & 505 & 660 \\
\hline
\end{tabular}

series concrete rapid freeze-thaw chamber produced by Beijing Shuzhi Yilong Instrument Co. Ltd.

\section{Results and Discussion}

\subsection{Performance Indexes of Coal Gangue Concrete under Freeze-Thaw Cycles}

3.1.1. Capillary Water Absorption Properties at Early FreezeThaw Stage. The water absorption of concrete is determined by ASTM C1585 [10], drawing the curves of $I$ and $t^{1 / 2}$ (between adsorption ratio and time). From Figure 2, it can be seen that, under the same freeze-thaw cycle times, adsorption ratios of CGCC with different MT content show the same rule; that is, the adsorption ratio of concrete increases with the increase of water absorption time. Moreover, all $I-t^{1 / 2}$ curves have inflection points, and the growth rate of the adsorption ratio changes from large to small. Moreover, it can be seen that the adsorption ratio of CGCC shows the trend of C0M6 > C0M2 > C0M4 > C0 with the increase of MT content. 


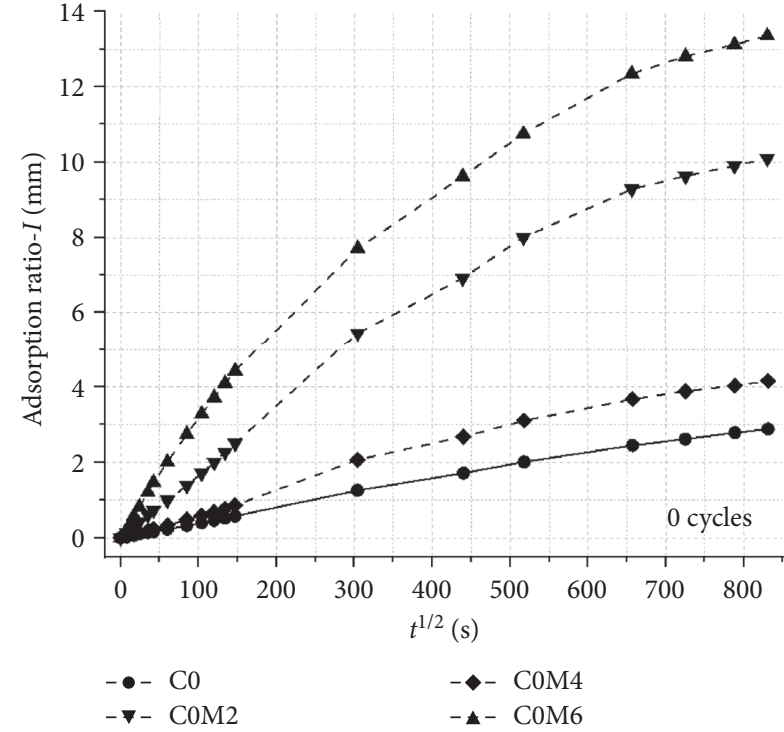

(a)

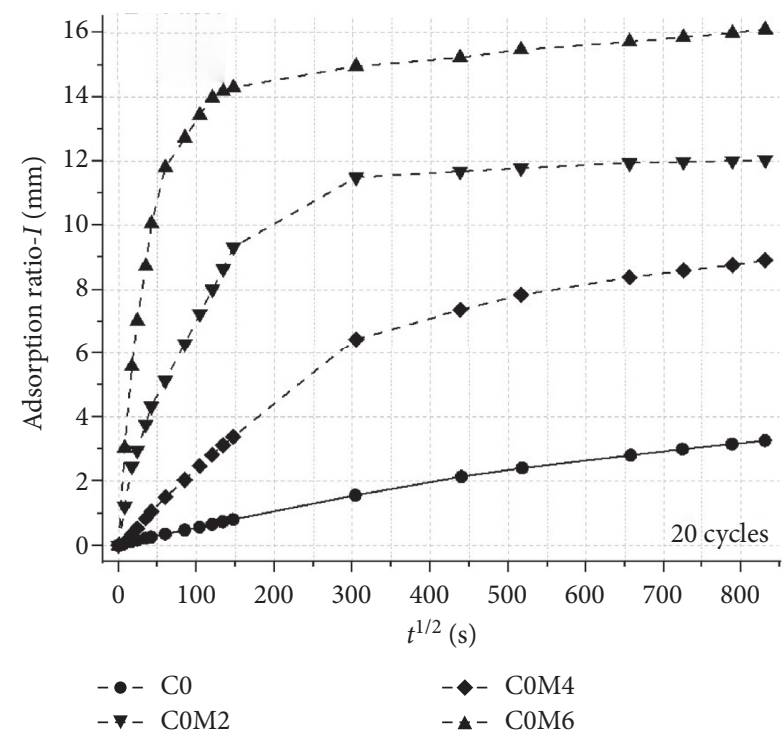

(c)

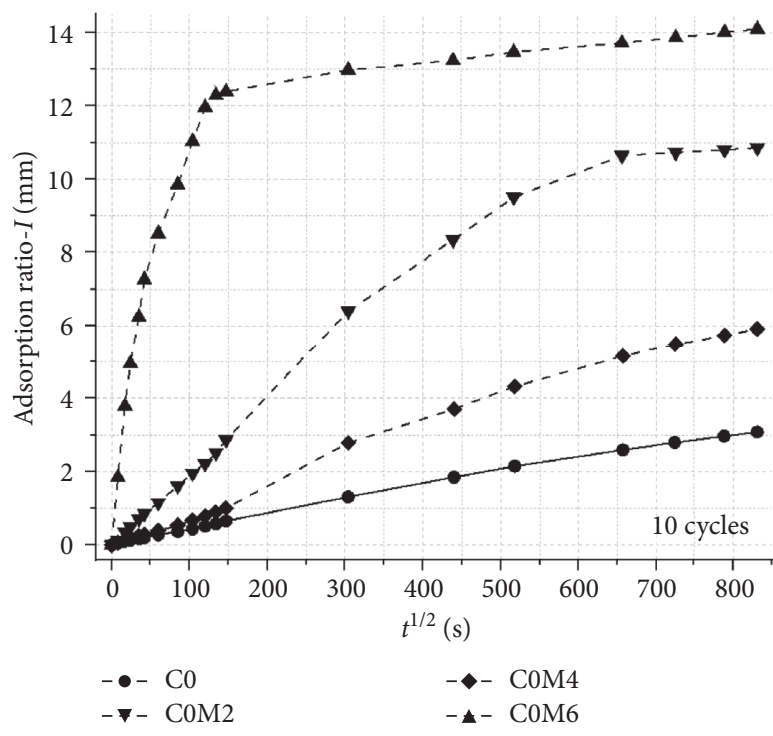

(b)

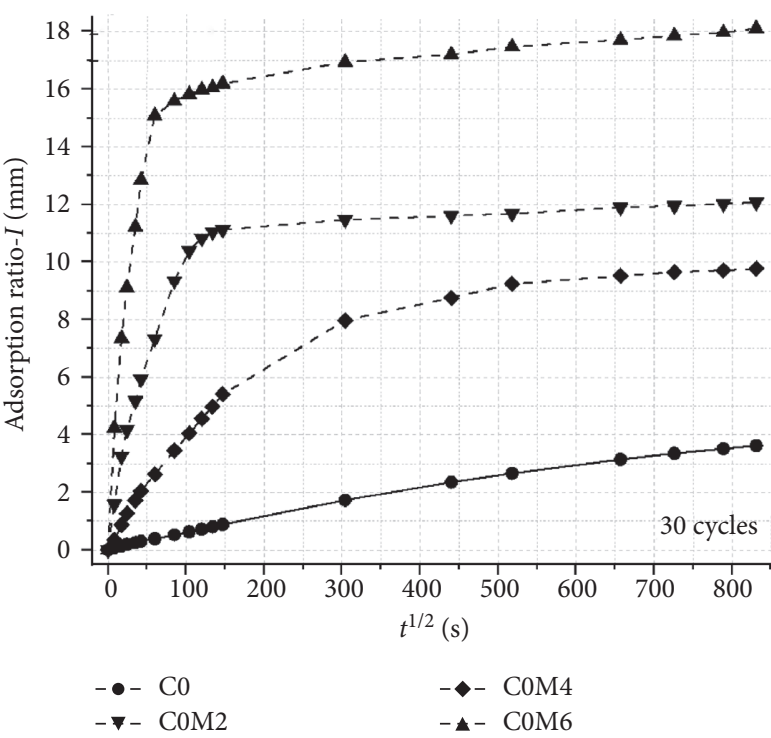

(d)

FIGURE 2: $I-t^{1 / 2}$ curve.

From Figure 2(a), under the unfrozen condition, the adsorption ratio of $\mathrm{C} 0$ is the smallest, which indicates that the ordinary concrete aggregate is dense. As shown in Table 4, the saturated water absorption ratio of common aggregates is much lower than that of gangue ceramics. However, the adsorption ratio of COM4 is lower than that of COM2 and C0M6, indicating that when MT content is $40 \%$, the effect of "micropump" of ceramite (capillary water absorption and desorption of ceramite) is better than that of C0M2 and C0M6 and makes concrete have strong "self-curing" capacity inside concrete [11]. It can be seen from Figures 2(b)-2(d) that the adsorption ratio of COM4 is lower than that of COM2 and C0M6 after freeze-thaw cycles and the adsorption ratio of $\mathrm{C} 0$ is the smallest. For detailed analysis, see section "4."
TABLE 4: Water absorption ratio $\omega$ of saturated coarse aggregate.

\begin{tabular}{lccccc}
\hline Specimen type & Gravel $(\mathrm{g})$ & Coal gangue $(\mathrm{g})$ & $m_{1}(\mathrm{~g})$ & $m_{2}(\mathrm{~g})$ & $\omega(\%)$ \\
\hline C0 & 400 & 0 & 414 & 407.5 & 1.6 \\
C0M2 & 320 & 58 & 395 & 373.5 & 5.8 \\
C0M4 & 240 & 115.7 & 390.5 & 350 & 11.6 \\
C0M6 & 160 & 173.6 & 379 & 326 & 16.3 \\
\hline
\end{tabular}

3.1.2. Relative Dynamic Elastic Modulus (RDM). Tests are set to end when the dynamic elastic modulus of the specimen decreases below $60 \%$ or the freeze-thaw cycle reaches 300 times, in which the dynamic modulus which drops below $60 \%$ is regarded as freeze-thaw failure. 
From Figure 3, with the increase of freeze-thaw cycle times, relative dynamic elastic modulus $\left(P_{n}\right)$ of CGCC with different contents decreases. Moreover, the decreased amplitude of CGCC is significantly greater than that of OC. Among them, the decrease of MT content in $60 \%$ is the fastest and that of $40 \%$ is the slowest. This phenomenon indicates that the addition of MT has an influence on the frost resistance of concrete and reduces it.

Among them, after 150, 200, and 100 freeze-thaw cycle times, the relative dynamic elastic modulus of COM2, COM4, and $\mathrm{C} 0 \mathrm{M} 6$ decreases to $56.1 \%, 55 \%$, and $51.1 \%$, respectively, which reach the freeze-thaw failure of $P_{n}$ lower than $60 \%$. $\mathrm{RDM}$ of $\mathrm{C} 0$ specimens changes little after 300 freeze-thaw cycles, $P_{n}$ only decreases by $8.5 \%$, and the specimens do not reach freeze-thaw failure.

3.1.3. Ratio of Mass Loss. According to the frost resistance requirements of concrete, the concrete mass loss shall not exceed $5 \%$ within a certain number of freeze-thaw cycles.

As shown in Figure 4, the mass of CGCC with different MT replacement ratios gradually increases with the increase of the number of freeze-thaw cycles. After 150, 200, and 100 freeze-thaw cycles, mass of CGCC increases by $0.415 \%$, $0.615 \%$, and $0.585 \%$, respectively. Due to the high water absorption ratio of MT, with the increase of freeze-thaw cycles and the evolution of internal pores inside the concrete, the mass of water absorption of MT is higher than that of mortar and ceramics peeled off the surface of concrete, which gradually increases the mass of concrete. Before 25 freeze-thaw cycles, the change trend of CGCC and OC curve is the same. Mass of $\mathrm{C} 0$ concrete specimens increases slightly before 25 freeze-thaw cycles because damage and microcracks inside the concrete absorb a part of water and increase its mass at the early stage of freeze-thaw. With the increase of the number of freeze-thaw cycles, internal cracks gradually develop, and more and more mortar flakes off the surface of concrete, resulting in a gradual decrease in its mass.

\subsection{Changes of Pore Structure}

3.2.1. Microstructure of CGCC. Microstructure and structural characteristics of OC and CGCC are shown in Figures 5 and 6. From the microstructure of concrete shown in Figure $5(500 \mathrm{x})$, both OC and CGCC have a lot of fine pores on their surfaces, but micropores of $\mathrm{C} 0$ are mainly inside the cement matrix so that $\mathrm{C} 0$ has a higher aggregate density than CGCC. This indicates that, after freeze-thaw cycles, the internal damages of $\mathrm{OC}$ are mainly inside the cement matrix. Combined with Figure 6 (2000x), it can be seen that CGCC micropores will develop inside both aggregate and concrete matrix, which indicates that micropores will develop inside MT under freeze-thaw cycles.

3.2.2. Changes of Pore Structure inside MT. From Table 4 and "3.1," it can be seen that the water absorption ratio of MT is higher than that of ordinary gravel. Furthermore, through the freeze-thaw test on MT, it is found that the

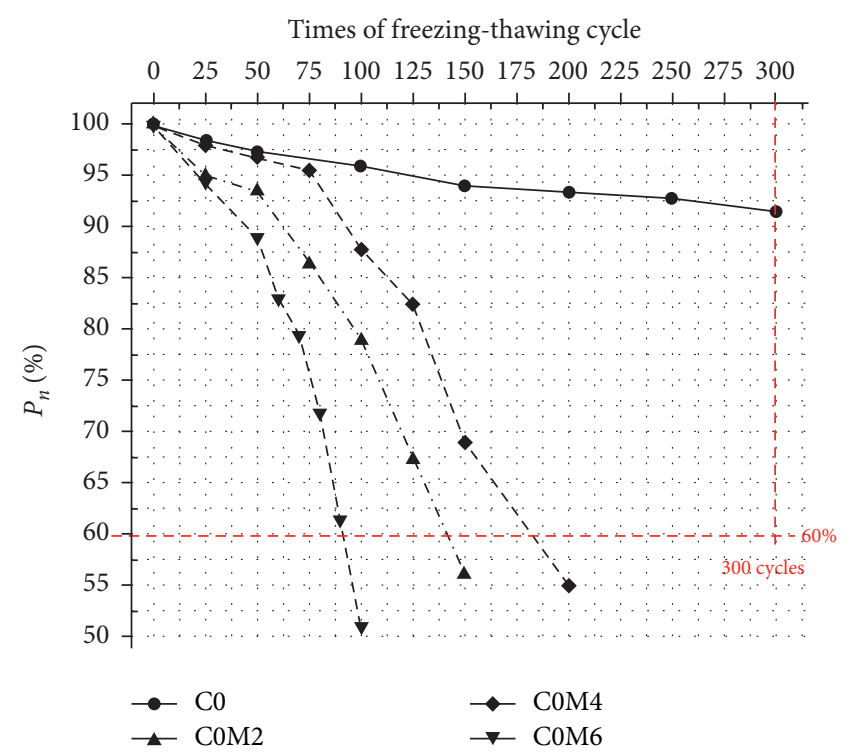

FIgURE 3: Variation law of relative dynamic elastic modulus $\left(P_{n}\right)$ with freeze-thaw cycle times.

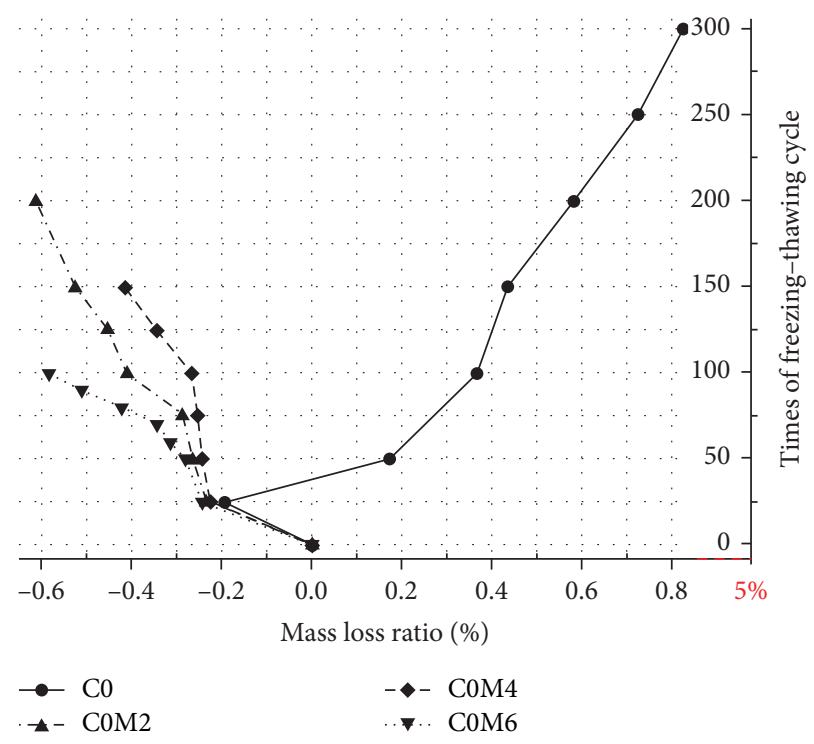

Figure 4: Mass loss ratio of different coal gangue replacement ratios under freeze-thaw cycles.

integrity of MT is greatly damaged after 50 freeze-thaw cycles, and some ceramics are crushed (as shown in Figure 7).

After $\mathrm{N}_{2}$ adsorption tests on MT, it can be seen from Figure 8(a) that the isothermal adsorption-desorption curves of MT before and after freeze-thaw cycles belong to type IV isothermal adsorption curve. In the range of relative pressure $\left(P / P_{0}\right)$ of $0.45-1.0$, obvious hysteresis loop structures could be observed, indicating that MT belongs to mesoporous structure, and the mesoporous structure in MT would not disappear after freeze-thaw cycles. Adsorption loops belong to Class B loops, and most of the pore structures are slot holes of a flat structure. Figure 8(b) shows 


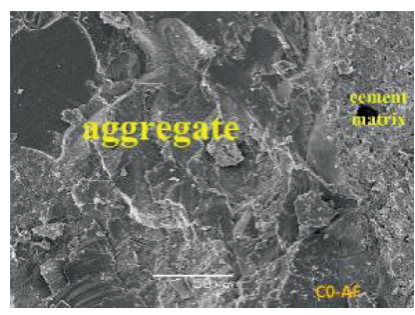

(a)

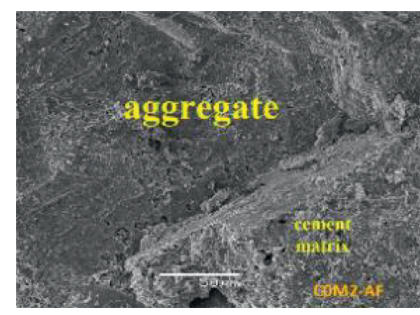

(b)

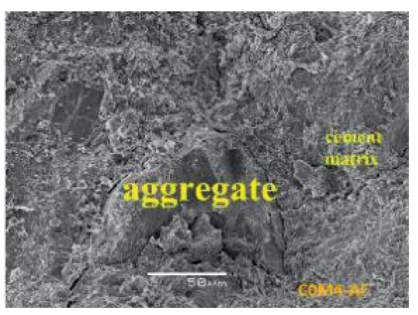

(c)

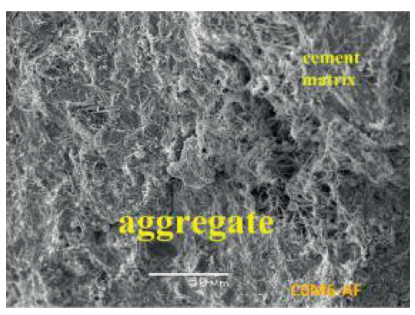

(d)

Figure 5: Characteristics of microstructure of CGCC after freeze-thaw cycles (500x).

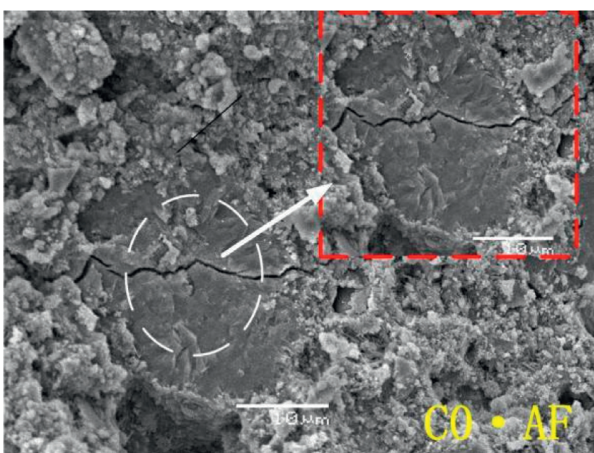

(a)

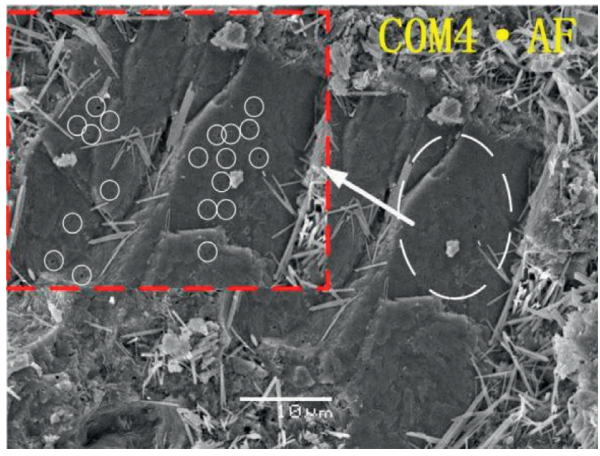

(c)

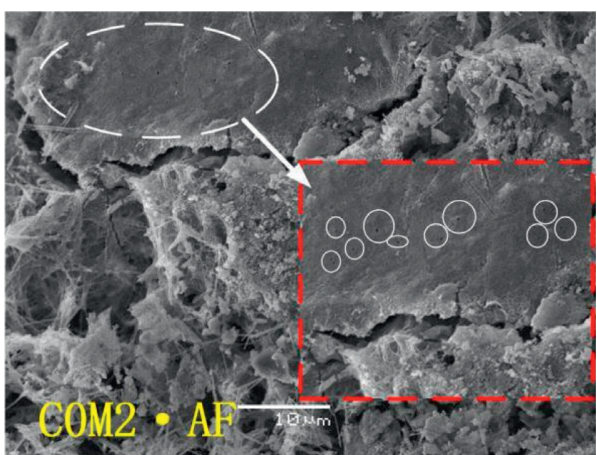

(b)

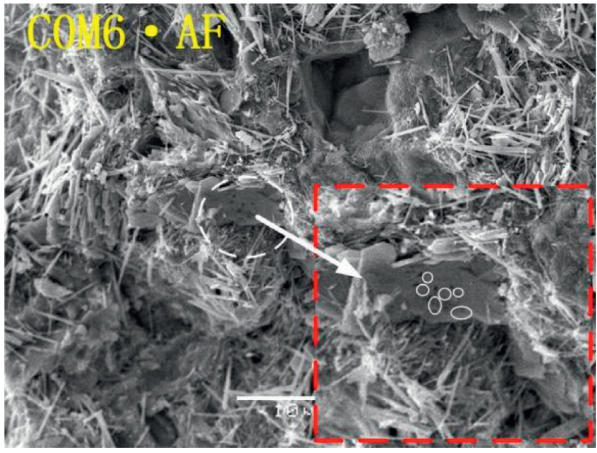

(d)

Figure 6: Characteristics of the microstructure of CGCC aggregate after freeze-thaw cycles (2000x).

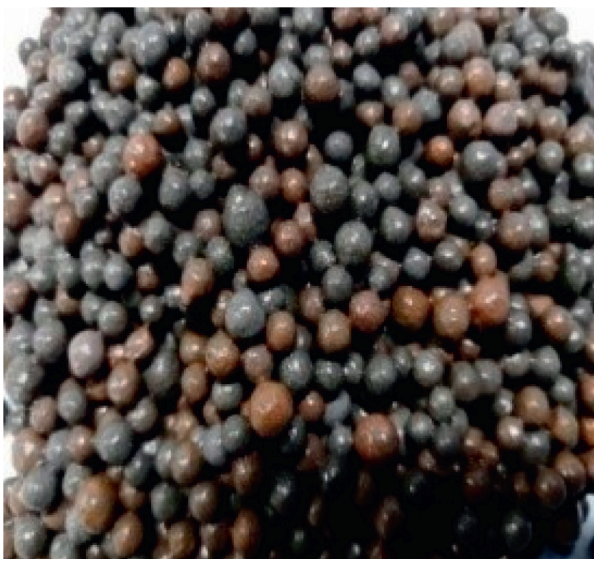

(a)

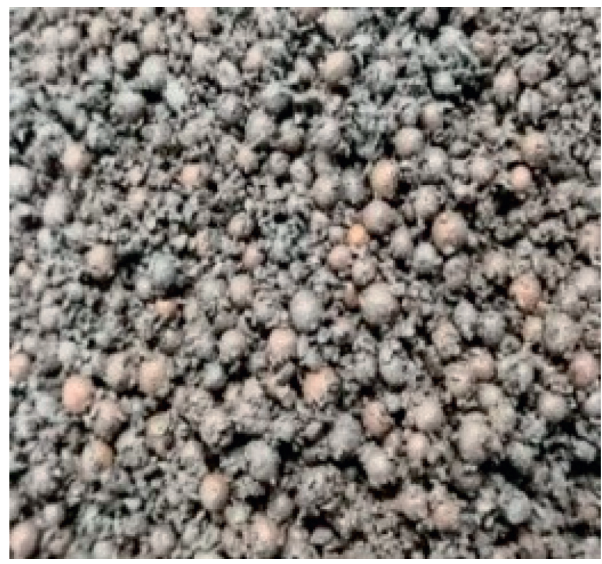

(b)

FIGURE 7: Coal gangue ceramsite under freeze-thaw cycles. (a) Unfrozen coal gangue ceramsite. (b) Coal gangue ceramsite under 50 cycle times. 


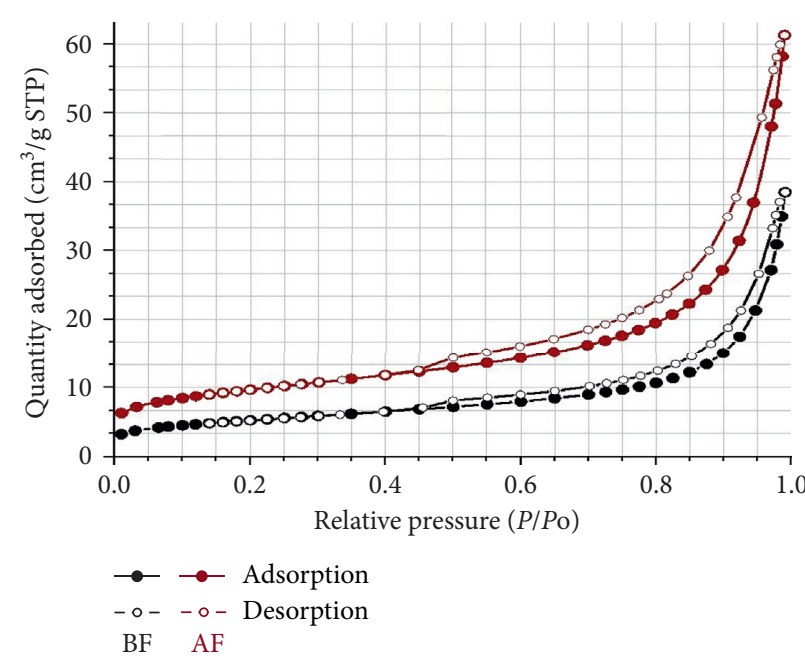

(a)

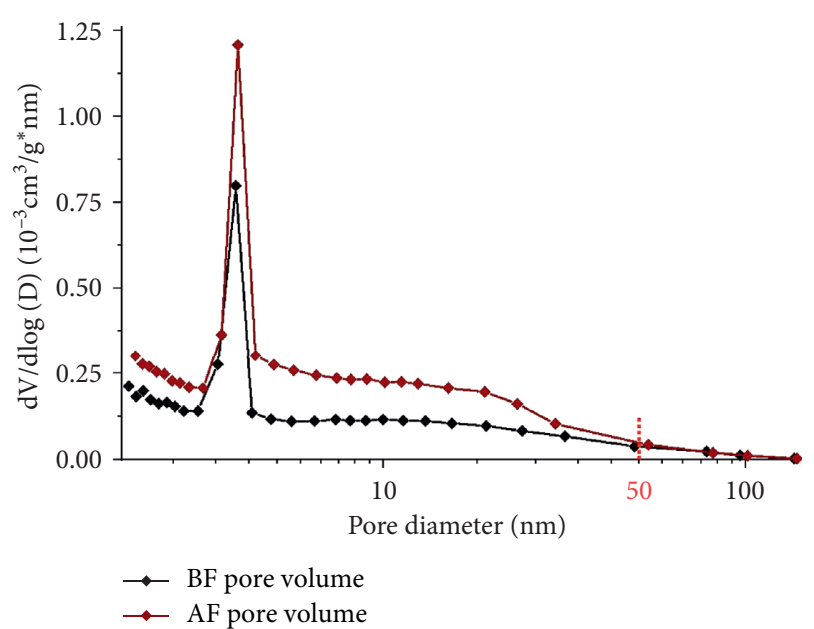

(b)

FIgURE 8: Curve of $\mathrm{N}_{2}$ adsorption $(77 \mathrm{~K})$ and pore diameter distribution of MT before and after freeze-thaw cycles.

the pore size distribution curve of MT before and after freeze-thaw cycles based on the BJH model. The changes of mesoporous pore size are mainly less than $50 \mathrm{~nm}$ before and after freeze-thaw cycles, most of which are in the range of 3-5 $\mathrm{nm}$. Therefore, the CGCC specimens with pore diameter less than $50 \mathrm{~nm}$ before and after freeze-thaw cycles should be reclassified in the way of pore diameter distribution of MT, as shown in Figure 9(a). Referring to IO.M. Butt's pore classification method, the overall pore diameter distribution of specimens is reclassified as shown in Figure 9(b).

3.2.3. Changes of Pore Structure inside CGCC. From Figures 7 and 9(a), the pores mainly developed inside MT with pore diameter less than $5 \mathrm{~nm}$ are called "M pores." After freeze-thaw cycles, the order of the ratio of $\mathrm{M}$ pores to total pore volume is COM2 $>\mathrm{COM} 6>\mathrm{C} 0 \mathrm{M} 4>\mathrm{C} 0$. Although $\mathrm{M}$ pores account for a small proportion of the total, $\mathrm{M}$ pores account for a large proportion of MT, which has a greater influence on the CGCC than capillary pores. The pores with pore diameters of 5-50 $\mathrm{nm}$ are called "T pores." After freezethaw cycles, the order of the ratio of T pores to total pore volume is $\mathrm{COM} 2>\mathrm{COM} 6>\mathrm{C} 0 \mathrm{M} 4>\mathrm{C} 0$. As shown in Figure 9(b), T pores are the main developing pores inside CGCC, accounting for about $45 \%$. So that $\mathrm{T}$ pores have a greater influence on the CGCC than capillary pores. Therefore, for CGCC, with the increase of MT content, the order of influence of different pore sizes on concrete is $\mathrm{T}$ pore $>M$ pore $>$ capillary pore $>$ large pore $>$ transitional pore, which explains that the initial adsorption ratio of C0M4 is less than that of C0M2 and C0M6 in Section 3.1.1. Due to the existence of MT, the adsorption of M pores and $\mathrm{T}$ pores is stronger than that of capillary pores inside CGCC. Therefore, CGCC concrete performs best when MT content is $40 \%$.

\section{Failure Mechanism under Freeze-Thaw Cycle Action}

Pore pressure includes pore water pressure and pore air pressure. Since concrete is saturated during the freeze-thaw cycle, there is only pore water pressure $U$ in concrete. Pore water pressure can be generated not only by external loads but also by freeze-thaw cycle action. Fagerlund [12] assumed a model as shown in Figure 10.

Assume that the distance between two pores in concrete is $l$. Due to capillary water absorption, concrete becomes saturated, and then water in the freezing-thawing environment starts to freeze in the pores. At a point "a" between the pores, the distance from one end of the pores is $x$, and the pressure generated by freezing is $u$.

Bai et al. [7] proposed that $\mathrm{u}$ is generated inside saturated concrete under the action of external load; that is, concrete is in the state of spherical stress and concrete matrix is compressed. As shown in Figure 11(a), it is assumed that saturated concrete consists of flawless concrete matrixes and spherical pores, and the total stress acting on the cross section is $\sigma$, which is assumed by the stress of the concrete matrix and the pore water pressure generated by the saturated water in the pores; that is,

$$
\sigma=\sigma^{\prime}+n u
$$

where $\sigma$ is the total stress of the cross section; $\sigma^{\prime}$ is the average stress assumed by the concrete matrix on the cross section $1-1, \sigma^{\prime}=\sigma_{s}(1-n) ; \sigma_{s}$ is the normal stress acting on the indirect contact surface of the concrete matrix; $n$ is the porosity; $u$ is the pore water pressure.

When concrete is placed in water environment, due to the capillary water absorption, the concrete absorbs water to the saturated state. Among them, the water in the large pores 


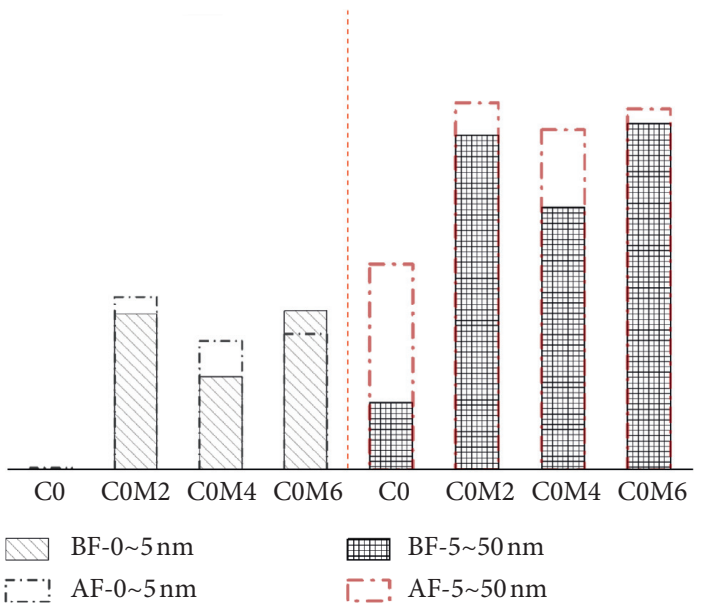

(a)

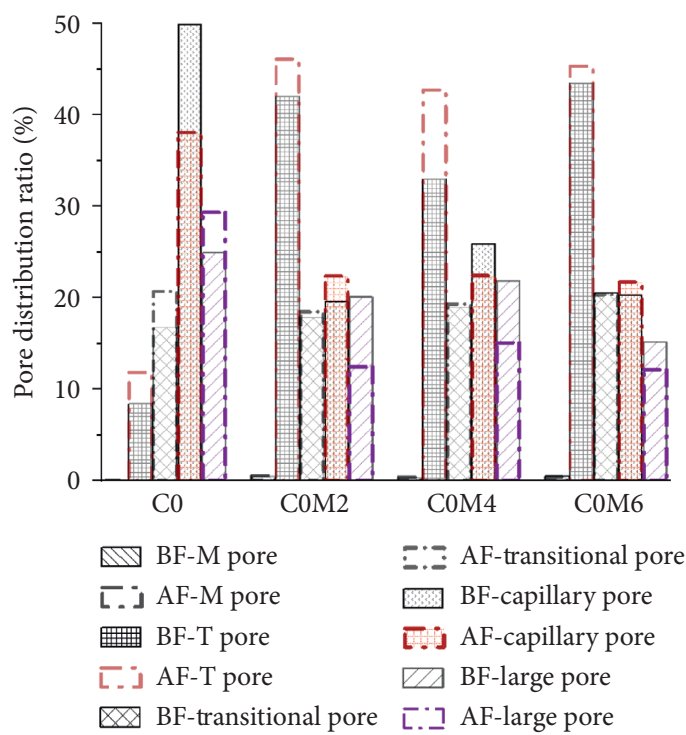

(b)

FIGURE 9: CGCC pore diameter redistribution diagram $(<5,5-50 \mathrm{~nm})$ and porosity distribution (histogram) before and after freeze-thaw cycles. PS: M pore: $<5 \mathrm{~nm}$; T pore: $5-50 \mathrm{~nm}$; transitional pore: $50-100 \mathrm{~nm}$; capillary pore: $100-1000 \mathrm{~nm}$; large pore: $>1000 \mathrm{~nm}$.
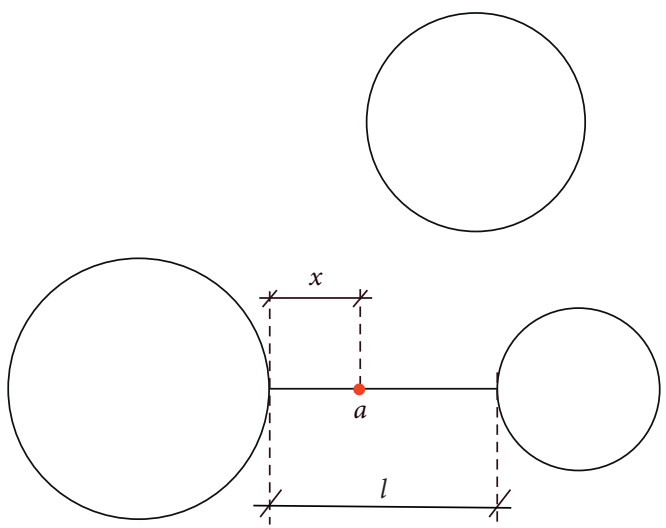

Figure 10: Pore model.

is frozen first. During the freezing process, due to the expansion of frozen water into ice, the unfrozen water in the fine pore permeates into the coarse pore to form hydrostatic pressure, i.e., in [13]. Since the deviatoric stress does not generate pore water pressure, the shear phenomenon of the material can be neglected, and the shear shrinkage phenomenon of the material can be neglected. And because it is equal in all directions, the total stress of the section caused by the external load can be regarded as the force due to frost heaving, as shown in Figure 11(b); that is,

$$
\sigma_{d}=\sigma^{\prime}+n u_{d},
$$

where $\sigma_{d}$ is the frost heaving stress on the cross section; $\sigma^{\prime}$ is the average stress of matrix at cross section 2-2, $\sigma^{\prime}=\sigma_{s}(1-n) ; n$ is porosity; and $u_{d}$ is pore water pressure.

Figure 12 shows the pore changes of $\mathrm{C} 0$ under freezethaw cycle action in 2.2. Details of internal pores at the initial stage (0 freeze-thaw cycles) are shown in Figure 12(a).
Capillary pores exist in the inner space of concrete which is filled by unhydrated products [14]. And they are distributed between the unhydrated cement particles and aggregate in the center of the cement matrix and account for $49.9 \%$ of the pore volume of OC. Transition pores exist between gel particles [14]. T pores are mostly connecting pores between gel particles, so they are evenly distributed on the edge of the cement matrix. There are also some large pores, accounting for $24 \%$ of the pore volume. The water absorbed by the concrete specimens fills all the open holes, making the specimen saturated. After the freeze-thaw cycle, the pores inside the concrete begin to change, as shown in Figure 12(b). Some capillary wall cracks are caused by extrusion pressure $u_{d}$ of water inside pores under freeze-thaw cycle action and some cracks and tiny pores appear inside the concrete cement matrix. As the number of freeze-thaw cycles increases, the frost heaving failure intensifies, as shown in Figure 12(c). When concrete is damaged under 


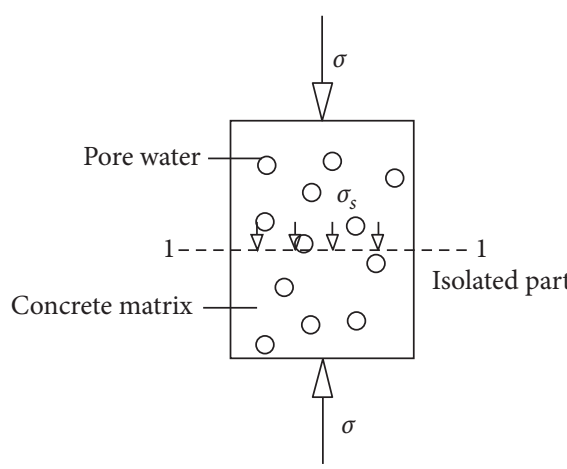

(a)

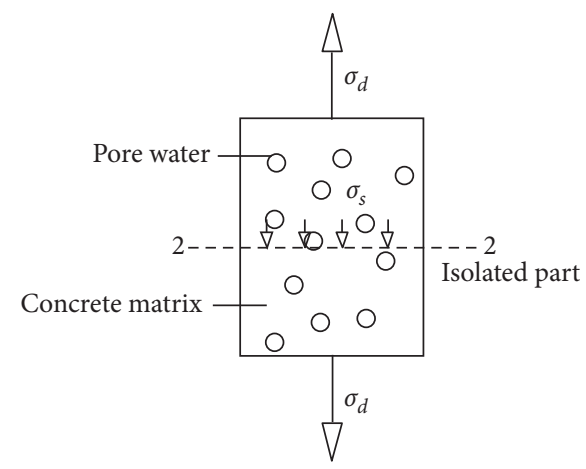

(b)

FIGURE 11: Schematic diagram of effective stress principle of concrete.
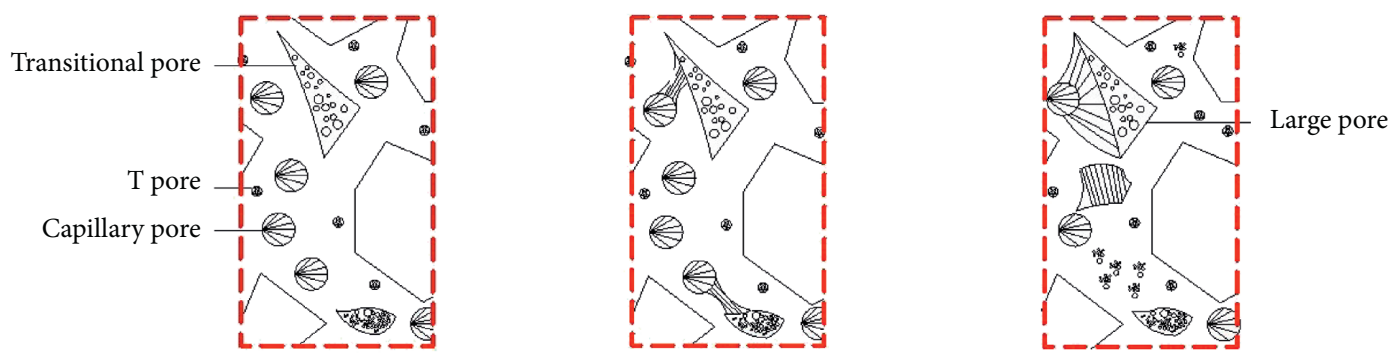

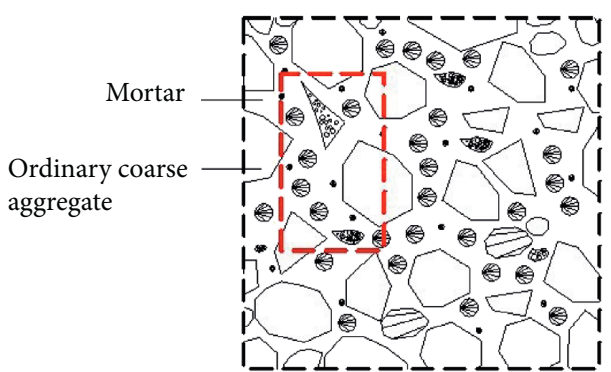

(a)

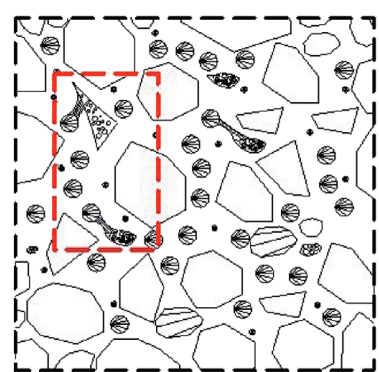

(b)

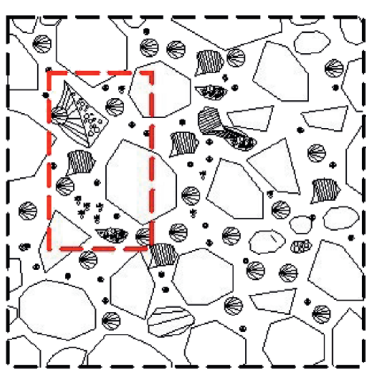

(c)

FIgURE 12: Schematic diagram of internal variation of ordinary concrete C0 freeze-thaw.

freeze-thaw action, the inner capillary pore walls are destroyed and connect with gel pores and adjacent pores to form large pores [15], which results in the increase of large pores and the decrease of capillary pores. Finally, the freezethaw cycle action leads to the decrease of capillary pores and the increase of large pores and T pores in OC. Concrete is destroyed when water pressure generated by freezing deterioration of pore structures exceeds the strength of concrete.

Taking C0M4 as an example, the pore distribution of CGCC under freeze-thaw cycle action is shown in Figure 13. Details of internal pores at the initial stage (0 freeze-thaw cycles) are shown in Figure 13(a). Ordinary coarse aggregates are occluded on contact surfaces. Due to the smooth spherical characteristics of MT, MT are point-to-point contacted. MT filled in the gap between ordinary aggregates make the distribution of coarse aggregates dense and the mortar can wrap the aggregate more fully. Moreover, when the distribution of aggregates becomes dense, the cement matrix becomes dispersed, and $\mathrm{T}$ pores are dominant, accounting for $32.9 \%$. Under frozen-thaw cycle action, the internal pores of saturated test specimens turn to change, as shown in Figure 13(b). Some capillary wall cracks are caused by extrusion pressure $u_{d}$ of water inside pores under freezethaw cycle action and some cracks appear inside the concrete cement matrix. The pore walls of M pores in MT also turn to crack due to water absorption and freeze-thaw cycle action. As the number of freeze-thaw cycles increases, the frost heaving failure intensifies, as shown in Figure 13(c). When concrete is damaged under freeze-thaw action, the inner capillary pore walls are destroyed and connect with gel pores and adjacent pores to form large pores, which results in the 

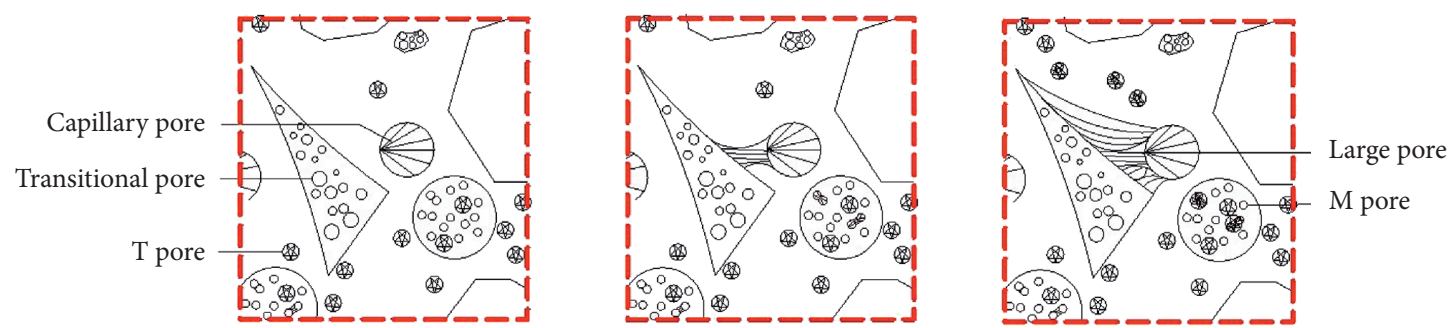

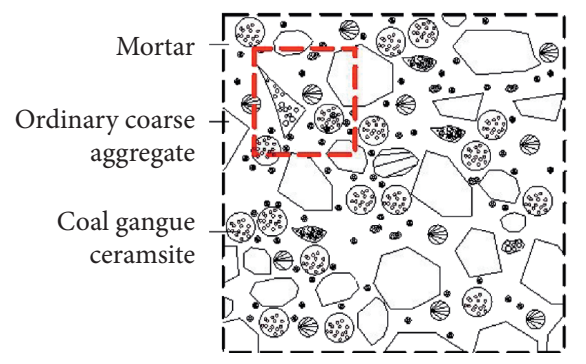

(a)

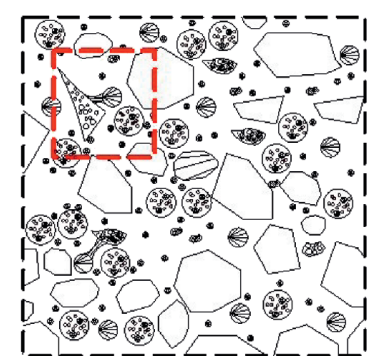

(b)

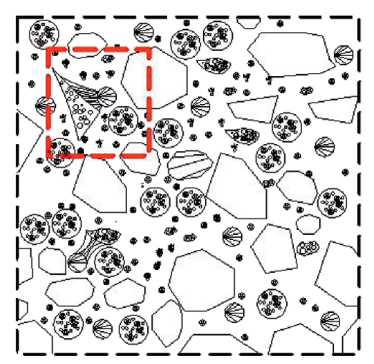

(c)

FIGURE 13: Schematic diagram of internal variation of coal gangue ceramsite concrete freeze-thaw.

increase of large pores. Meanwhile, part of M pores in MT is interconnected into T-holes. Finally, the freeze-thaw cycle action leads to the increase of large pores and $\mathrm{T}$ pores in CGCC and the majority of pores are T pores. The surface of the water in the pores of the concrete structure is curved, which could reduce the freezing point of pore water inside the structure. Moreover, the smaller the pore radius is, the lower the freezing point of pore water is and the lower the probability of pore water freezing into ice is [15]. Therefore, because the internal pores of CGCC structure tend to be small, the freezing point of pore water is reduced, the damage to concrete caused by freezing is reduced, and the frost resistance of concrete is improved.

\section{Conclusions}

(1) After freeze-thaw cycle action, each performance index of CGCC changes significantly, among which the performance is best when the mixing amount is 40\%. CGCC with different MT dosage (20\%, 40\%, and $60 \%)$ reach freeze-thaw failure after 150, 200, and 100 freeze-thaw cycles, respectively. Under the same freezing-thawing environment, the adsorption rate of CGCC with different MT dosage increases with the increase of water absorption time, and the order of magnitude is C0M6 $>\mathrm{COM} 2>\mathrm{C} 0 \mathrm{M} 4>\mathrm{C} 0$. After the freeze-thaw cycle action, with the increase of the number of freeze-thaw cycles, the relative dynamic elastic modulus and compressive strength gradually decrease. And the reduction of CGCC is significantly greater than that of OC.

(2) The development of T-hole has different effects on MT and concrete matrix. T-holes in the concrete matrix can mitigate the deterioration to some extent. The pores in OC are dominated by capillary pores. After freeze-thaw cycles, capillary pores decrease and large pores and $\mathrm{T}$ pores increase. Water pressure caused by the deterioration and freezing of pore structure exceeds the strength of concrete; that is, concrete is destroyed. However, CGCC is dominated by T-holes due to the special aggregate shape. After freezing-thawing cycle, T-holes increase and large holes decrease slightly. Among them, the degradation mitigation effect is better when the coal gangue ceramsite content is $40 \%$.

(3) Due to the special shape of MT material, the pores of concrete matrix develop from large pores to small pores with the addition of MT, leading to the change of microstructure of concrete matrix, thus improving the structural deterioration caused by freeze-thaw. Among the three kinds of contents, $40 \%$ is the most effective.

\section{Data Availability}

The research data used to support the study are available from the corresponding author upon request by email.

\section{Conflicts of Interest}

The authors declare that they have no conflicts of interest.

\section{References}

[1] China National Coal Association (CNCA), Annual Report of Coal Industry Development in 2019, China National Coal Association (CNCA), Taiyuan, China, 2020.

[2] X. Duan, J. Xia, and J. Yang, "Influence of coal gangue fine aggregate on microstructure of cement mortar and its action mechanism," Journal of Building Materials, vol. 17, no. 4, pp. 700-705, 2014.

[3] X. Duan, Study on the Micro-structure and Physical-Mechanical Performance of Concrete with Coal Gangue as 
Aggregate, China University of Mining and Technology, Xuzhou, China, 2014.

[4] M. Zhou, Z. Li, Y. Wu et al., "Experimental research on limefly ash-cement stabilized coal gangue mixture," Journal of Building Materials, vol. 13, no. 2, pp. 213-217, 2010.

[5] J. Zheng, Capillary Water Absorption Properties of Coal Gangue Concrete under Freeze-Thaw Cycles, Xi'an University of Science and Technology, Xi'an, China, 2018.

[6] J. Bao, Z. Yu, P. Zhang, S. Li, and T. Zhao, "Review on the frost resistance property of recycled coarse aggregate concrete and its structural components," Journal of Building Structures, 2020.

[7] W. Bai, W. Xie, J. Guan et al., "Influence of pore water pressure on compressive strength of concrete under complicated stress states," Journal of Building Materials, vol. 18, no. 1, pp. 28-34, 2015.

[8] X. Du and J. Liu, "Research on the effective modulus and tensile strength of saturated concrete," Journal of Hydraulic Engineering, vol. 43, no. 6, pp. 667-674, 2012.

[9] C. Tan, Research on Non-clay Ceramisite and its Concrete Performance, Harbin Institute of Technology, Harbin, China, 2010.

[10] ASTM C1585, Standard Test Method for Measurement of Rate of Absorption of Water by Hydraulic Cement Concretes, ASTM International, West Conshohocken, PA, USA, 2013.

[11] S. Chen and W. Chen, "Study on micropumping effect of ceramsite," Journal of Civil and Environmental Engineering, vol. 3, pp. 31-43, 1983.

[12] Z. Wu and H. Lian, High Performance Concrete, China Railway Publishing House, China, 1999.

[13] Q. Meng, Research of Influencing Factor between Concrete Durability And Pore Structure, Harbin Institute of Technology, Harbin, China, 2006.

[14] B. Xv, Analysis of Freeze-Thaw Failure Mechanism of Concrete Mixed with Diatomite, Jilin University, Changchun, China, 2019.

[15] S. Li, T. Zhao, and K. Wu, "Relationship between permeability and microstructure of concrete," China Concrete and Cement Products, vol. 2, pp. 6-8, 2004. 